\title{
Fundamentos histórico-sociológicos da pesquisa em práticas sociais e processos educativos
}

\author{
Historical-sociological foundations of research in social practices and educational processes \\ Fundamentos histórico-sociológicos de la investigación en prácticas sociales y procesos educativos \\ DiOgo MARQUeS TAFURI ${ }^{1}$ \\ Universidade Federal de São Carlos, UFSCar, São Carlos-SP, Brasil
}

\begin{abstract}
RESUMO
Neste artigo, buscamos evidenciar os fundamentos históricos e sociológicos das pesquisas que objetivam investigar processos educativos decorrentes de práticas sociais diversas, ocorridas no contexto escolar ou fora dele. Por meio de pesquisa bibliográfica e qualitativa, problematizamos as tensões existentes entre desigualdade social estruturante, escolarização e processos educativos não escolares, dando especial destaque às realidades brasileira e latino-americana. Argumentamos a favor da relevância acadêmica e social das pesquisas em Práticas Sociais e Processos Educativos para o debate científico realizado na área da Educação, em sua contribuição específica para os estudos acadêmicos que propõem uma compreensão histórico-sociológica da educação brasileira.
\end{abstract}

Palavras-chave: Processos Educativos. Práticas Sociais. Educação Brasileira.

\begin{abstract}
In this paper, we highlight the historical and sociological foundations of research that investigate educational processes arising from different social practices, which occurred in or outside the school context. Through bibliographic and qualitative research, we problematize the existing tensions between structuring social inequality, schooling and non-school educational processes, with special emphasis on the Brazilian and Latin American realities. We argue in favor of the academic and social relevance of research in Social Practices and Educational Processes for the scientific debate held in the area of Education, in its specific contribution to academic studies that propose a historical-sociological understanding of Brazilian education.
\end{abstract}

Keywords: Educational Processes. Social Practices. Brazilian Education.

\section{RESUMEN}

En este artículo buscamos resaltar los fundamentos históricos y sociológicos de las investigaciones que tienen como objetivo estudiar los procesos educativos que surgen de diferentes prácticas sociales, ocurriendo dentro o fuera del contexto escolar. A través de la investigación bibliográfica y cualitativa, problematizamos las tensiones existentes entre la estructura de desigualdad social, la escolarización y los procesos educativos no escolares, con especial énfasis en las realidades brasileñas y latinoamericanas. Argumentamos a favor de la relevancia académica y social de la investigación en Prácticas Sociales y Procesos Educativos para el debate científico realizado en el área de Educación, en su contribución específica a estudios académicos que proponen una comprensión histórico-sociológica de la educación brasileña.

Palabras clave: Procesos Educativos. Practicas Sociales. Educación Brasileña.

\footnotetext{
${ }^{1}$ Doutor em Educação (PPGE/UFSCar). E-mail: diogotafuri@gmail.com. ORCID: https://orcid.org/0000-0003$\underline{0880-1243 .}$.
} 


\section{INTRODUÇÃO}

O presente artigo pretende contribuir com o debate científico realizado no âmbito dos estudos acadêmicos da área da Educação, em específico com aqueles que privilegiam um enfoque sociológico da história da educação brasileira. Tal intenção será possibilitada por meio de discussão bibliográfica orientada para a elaboração de fundamentos históricos e sociológicos das pesquisas que objetivam investigar processos educativos decorrentes de práticas sociais diversas, ocorridas no contexto escolar ou fora dele. Partiremos, especificamente, do diálogo entre a literatura especializada e os conhecimentos acumulados por comunidade de trabalho ${ }^{2}$ que tem investigado processos educativos presentes em práticas sociais, instituídas nas relações tecidas entre pessoas no interior de grupos, comunidades de pertencimento e instituições sociais, e situadas no seio da estrutura social que se constitui enquanto totalidade (SILVA, 1987; 2014; OLIVEIRA et al., 2014).

O texto está organizado em sete partes distintas: além desta breve introdução (I), buscaremos evidenciar os elementos propriamente históricos e sociológicos inerentes às categorias analíticas práticas sociais e processos educativos (II), para em seguida promover a contextualização das formas de manifestação do fenômeno educativo na contemporaneidade, no que tange às relações estabelecidas entre instituições societárias e estrutura social (III), dando especial destaque às realidades brasileira e latinoamericana, marcadas desde o advento da modernidade pela colonialidade das relações de poder (IV); na sequência, problematizaremos a função educativa das instituições escolares de ensino a partir das relações que estabelecem com processos educativos não escolares (V), enfatizando o processo de constituição do campo pedagógico da Educação Popular e da Educação de Jovens e Adultos como fenômeno especialmente representativo das tensões existentes entre desigualdade social estruturante, escolarização e práticas sociais não escolares (VI); por fim, teceremos algumas considerações sobre a relevância acadêmica e social da pesquisa em Práticas Sociais e Processos Educativos no momento atual da história da educação brasileira (VII).

\section{A DIMENSÃo históRICO-SOCIOLÓgICA dAS PESQUiSAS EM PRÁtiCAS SOCIAIS E PROCESSOS EDUCATIVOS}

As reflexões aqui propostas têm o desígnio de promover tanto a síntese como a continuidade de quase 10 anos de pesquisa empírica e teórica do autor na área da Educação, período ao qual nos dedicamos a contribuir com o desvelamento de processos educativos decorrentes de práticas sociais populares, realizadas em bairro de periferia urbana (TAFURI, 2014; TAFURI; GONÇALVES JUNIOR, 2015) e em assentamento da reforma agrária (TAFURI, 2019; 2021; TAFURI; GONÇALVES JUNIOR, 2020) de um município de médio porte do estado de São Paulo. Neste sentido, uma primeira elaboração sintética já havia sido realizada em trabalho anterior (TAFURI; GONÇALVES JUNIOR, 2017), no qual apresentamos a experiência histórica de constituição desta perspectiva epistemológica de pesquisa em Educação, discutindo a intencionalidade original que fundamentou os princípios teóricometodológicos afins ao referido projeto científico; igualmente, aprofundamos o debate teórico-conceitual acerca das duas categorias analíticas centrais para a realização desta

\footnotetext{
2 A linha de pesquisa "Práticas Sociais e Processos Educativos" é composta por docentes e discentes do Programa de Pós-Graduação em Educação, da Universidade Federal de São Carlos (PPGE/UFSCar).
} 
proposta de investigação do fenômeno educativo: práticas sociais e processos educativos.

Sob o primeiro aspecto apontado, explicitamos como questão geradora do surgimento deste grupo de pesquisa a importância da compreensão de processos educativos alheios à escola, em sua relação com as condições pedagógicas encontradas dentro das salas de aula, para a promoção de processos de ensino-aprendizado efetivamente democráticos. Já no tocante ao aprofundamento da discussão teórica envolvendo as categorias referenciais apresentadas, ao refletirmos sobre alguns de seus elementos conceituais constitutivos, à luz dos aportes de Paulo Freire (2006; 2011), Ernani Maria Fiori (1991; 2014a; 2014b), Maurice Merleau-Ponty (2006), Enrique Dussel $(1977$; 1995) e Maria Waldenez de Oliveira e colegas (2014), elaboramos algumas formulações expressivas de uma proposta de compreensão analítica que pode vir a subsidiar a realização de tais estudos e pesquisas:

Ninguém se constitui como ser humano individualmente; ao contrário, é
somente a partir do encontro intersubjetivo de consciências que, a partir do
mundo consciente, engendramos práticas que subjetivam e objetivam nossa
forma de sermos-com-outrem-ao-mundo, através da comunicação dialógica.
Portanto, quando falamos em práticas sociais, pensamos em relações que se
estabelecem entre as pessoas, por meio da intencionalidade, que buscam
transformar a realidade vivida. Tais relações são mediatizadas por um mundo
comum que se expressa existencialmente (objetiva e subjetivamente) aos
participantes de tais relações por meio desta mesma práxis histórica, bem
como pela comunicação intersubjetiva exercida por meio do diálogo
(TAFURI; GONÇALVES JUNIOR, 2017, p. 44 ).

Os processos educativos, tomados como inerentes e decorrentes da práxis humana intersubjetiva de e na construção histórica do mundo, constituem-se na relação entre sujeitos cognoscentes mediatizada pelos objetos cognoscíveis, ou seja, pelas situações existenciais vivenciadas pelos sujeitos do ato cognoscente; configuram-se de modo autêntico enquanto situação gnosiológica na qual intersubjetivamente tais sujeitos desvelam de forma crítica a realidade problematizada, ao mesmo tempo em que re-elaboram o conhecimento existente e re-criam o mundo por meio de sua ação, que passa então a se constituir como práxis. [...] Este movimento em direção a um devenir da realidade, que parte da condição existencial humana desde um aqui e um agora, de um corpo-aqui e um mundo-aqui, se configura como uma sucessão de horizontes que continuamente vão se atualizando e, portanto, objetificando as possibilidades de poder-ser dispostas historicamente aos indivíduos como condicionalidades estruturais (TAFURI; GONÇALVES JUNIOR, 2017, p. 45-46).

Realizando alguns desdobramentos iniciais e possíveis das afirmações destacadas, considerando ainda a linha argumentativa proposta neste artigo, a configuração propriamente social das ações humanas, mediatizadas que são pela existência de um mundo comum que se apresenta enquanto realidade histórico-cultural produzida e intencionalmente transformada por ações e relações intersubjetivas, é o que permite afirmar o caráter propriamente sociológico do fenômeno educativo. Pois, se de um lado, os processo educativos podem ser compreendidos a partir de sua dimensão subjetiva relativa à formação anímica dos indivíduos, a qual se relaciona com a experiência de significação do mundo cultural e de constituição de suas identidades individuais e coletivas, de outro encontramos uma dimensão distinta, mas igualmente característica de tal fenômeno, representada pelos modos concretos de objetivação assumidos pelos processos sociais constitutivos da realidade que compartilhamos. Destarte, os processos educativos expressam a tensão existente entre os níveis subjetivo e intersubjetivo da 
ação humana, resultando em condições históricas sempre específicas que mediatizam as relações sociais.

A especificidade de tais condições advém, então, da temporalização que rege a possibilidade da existência humana, a qual se manifesta desde um projeto futuro que se configura a partir de uma realidade constituída pelos desdobramentos do passado que condiciona as possibilidades individuais e coletivas de existir ao mundo, e não de um presente abstrato. Portanto, além de se configurar enquanto objeto de conhecimento sociológico, a compreensão dos fenômenos educativos requer igualmente a explicitação de sua dimensão histórica.

\section{EDUCAÇÃO E INSTITUIÇÕES SOCIAIS NA CONTEMPORANEIDADE}

Propomos, assim, discutir a educação enquanto fenômeno ontológico, pois reconhecemos na abrangência e permanência dos processos educativos vivenciados por toda gente em práticas sociais espaço-temporalmente situadas, e em seu papel para conformação de formas individuais e coletivas de ser, agir, pensar, significar, transformar e transformar-se ao mundo, uma condição existencial comum e inerente a todos e a cada um dos seres humanos. Portanto, a noção de educação que estrutura este trabalho, definida como mediação fundamental da existência humana, baseia-se no pressuposto da existência reciprocamente constitutiva entre seres humanos e mundo objetivo, unidade existencial fundante que se realiza por meio da tensão entre o reconhecimento humano subjetivo da objetividade histórica e as suas possibilidades, também históricas, de objetivação da existência intersubjetiva (TAFURI, 2019). Segundo Flávio Brayner, em sua obra "Fundamentos da Educação" (2015):

\footnotetext{
Toda educação é, antes de qualquer coisa, um projeto de subjetivação que nos permite adquirir uma característica particular (individualização) no interior de uma rede ampla e complexa de significados, normas e relações (socialização). Sem isso, nós estaríamos condenados a uma espécie de retomo à Natureza e à condição animal. Assim, falar de educação é reconhecer que somos incompletos e inacabados, que somos herdeiros de um "mundo" e que precisamos cuidar dele e transmiti-lo para os mais novos - que sempre introduzirão nele, gostemos ou não, algo novo - e que as gerações que chegam aqui precisam ser introduzidas com cuidado e proteção. Esse processo não finda nunca; se a experiência escolar pode ter um fim, a experiência educativa é contínua e interminável (p. 23).
}

Se, do ponto de vista epistemológico, a própria dimensão social dos processos educativos terminou por configurar, no decorrer do desenvolvimento das ciências humanas, o fenômeno educativo enquanto objeto de conhecimento da sociologia, dada sua qualidade ontológica e totalizante, historicamente a reflexão sociológica sobre educação estabeleceu gradativamente seu foco na compreensão da instituição escolar. Marília Pontes Sposito (2003) afirma a pertinência do uso da expressão sociedade escolarizada para designar a centralidade adquirida pelas instituições de ensino enquanto referência identificatória do mundo moderno, mesmo reconhecendo a presença de agenciamentos diversos presentes no processo de formação $\mathrm{e}$ desenvolvimento das novas gerações, reiterando o argumento de que "[...] os mecanismos por meio dos quais uma sociedade transmite a seus membros seus saberes, o saber-fazer e o saber-ser que ela estima como necessários à sua reprodução são de uma infinita variedade" (SPOSITO, 2003, p. 211). 
Destacando as contribuições do sociólogo francês Émile Durkheim acerca da natureza sociológica da escola, a autora contextualiza os fundamentos normativos presentes na constituição histórica dos sistemas de ensino laicos na Europa Ocidental, os quais deveriam ter a capacidade de agenciar a existência moral do indivíduo moderno em sua inserção no espaço público:

É inegável que, ao definir a vida social pela densidade das trocas morais, Durkheim considerava a moral como essencialmente racional e de fundamento social, pressupondo nela três elementos: a disciplina que incide sobre a necessidade da autoridade impessoal e do domínio da regra e da lei na orientação da ação humana; a adesão aos grupos sociais que exprimiria o altruísmo em oposição ao egoísmo natural dos imaturos; e a autonomia da vontade, exprimindo o exame racional e a livre adesão às regras. Assim, o fundamento social da moral implicaria a ideia de que ela deveria ser explicada e ensinada, ou seja, objeto de ação deliberada das gerações adultas sobre as novas gerações, substituindo o lugar até então assumido pelos sistemas religiosos na formação das representações e da consciência coletiva (SPOSITO, 2003, p. 213).

Depreende-se do exposto um postulado extremamente relevante para refletirmos sobre o fenômeno educativo em sua forma mais abrangente, o qual foi utilizado por Florestan Fernandes (2004) para debater as possíveis relações entre universidade e desenvolvimento: as instituições-chave das sociedades devem ser tomadas, enquanto objeto sistemático de reflexão, como realidade histórico-social. Portanto, não somente tais instituições respondem a demandas oriundas do meio societário em determinado tempo-espaço, mas é a própria sociedade quem define estruturalmente (a partir das condições materiais e simbólicas disponíveis) o modo como se exprimem as relações entre meios e fins e seu impacto na funcionalidade de cada instituição específica, no que concerne ao atendimento das necessidades sociais para as quais elas foram criadas. Assim, para Fernandes, não é correto afirmar que o rendimento de uma instituição social dependa exclusivamente de sua organização e de seu dinamismo interno, visto que são as sociedades "[...] que determinam, por sua estrutura e evolução típicas, os ritmos das instituições" (FERNANDES, 2004, p. 275).

Para Fernandes (2004), a análise sociológica sobre a instituição escolar deve procurar analisar as relações existentes entre mudança social e mudança educacional, a fim de "[...] compreendê-la à luz de condições, fatores e influências que a projetam no cenário mais amplo das ações e das relações humanas. Ela não surge, como o "mundo em si e para si', da reflexão pedagógica. Mas como uma realidade histórico-social” (p. 276). A aceitação da existência desta permeabilidade entre elementos escolares e não escolares na constituição do fenômeno educativo, no que se refere às suas relações de condicionamento mútuo, ampliam a relevância da promoção de pesquisas cujas orientações epistemológicas se valem de uma perspectiva não escolar no estudo sociológico da escola e da educação, considerada em suas formas de manifestação mais abrangentes (SPOSITO, 2003). O impacto de tal posicionamento para as pesquisas em práticas sociais e processos educativos se mostram de modo mais evidente quando situamos, objetivamente, as questões educacionais brasileiras no seio da dinâmica real das relações de dependência no mundo capitalista subdesenvolvido, as quais vêm sendo continuamente rearticuladas sob a forma da colonialidade do poder $^{3}$ exercida por meio das bases institucionais nacionais dos países latino-americanos.

\footnotetext{
${ }^{3}$ Podemos compreender esta forma de poder globalmente hegemônica a partir da concepção de Anibal Quijano (2005): refere-se ao “[...] modo como foram configuradas as disputas pelo controle do trabalho,
} 


\section{ESTRUTURA SOCIAL, PODER E O "PROBLEMA EDUCACIONAL" NO BRASIL E NA AMÉRICA LATINA}

A acumulação do capital se impõe enquanto síntese social no Brasil e na América Latina, a ponto de Héctor Alimonda (2011) afirmar que “[...] el trauma catastrófico de la conquista y la integración en posición subordinada, colonial, en el sistema internacional, como reverso necesario y oculto de la modernidad, es la marca de origen de lo latinoamericano" (p. 21). Para o autor, a dominação colonial europeia do continente latinoamericano alterou profundamente os equilíbrios até então existentes nas relações estabelecidas entre os povos originários e seu meio natural, tomado em sua realidade biofísica (diversidade de ecossistemas) e configuração territorial (dinâmica sociocultural de interação e significação humana do ecossistema). A natureza latino-americana, desde então colonizada, transforma-se a partir do século XVI em território subalternizado, incorporado ao espaço hegemônico europeu enquanto extensão de terras tropicais aptas para produção de valores de troca em benefício do regime de acumulação vigente (ALIMONDA, 2011).

Segundo Quijano (2005), assistimos desde então à emergência de um novo padrão de poder globalmente hegemônico, responsável por conjugar o processo de exploração econômica das colônias americanas com uma forma historicamente específica de dominação cultural, o eurocentrismo, o que "[...] significou para esse mundo uma configuração cultural, intelectual, em suma intersubjetiva, equivalente à articulação de todas as formas de controle do trabalho em torno do capital" (p. 110). A associação imediata entre identidade racial e hierarquização social fundou a ideia de que os "níveis, lugares e papéis na estrutura de poder da nova sociedade" eram constitutivos da própria diferenciação racial existente entre os seres humanos, reforçando deste modo as relações sociais de dominação impostas pelos colonizadores. Com isso, concretizou-se o processo histórico de articulação das diversas formas de controle do trabalho colonial em particular (escravidão, servidão, pequena produção mercantil, reciprocidade e o salário) e do processo produtivo em geral, a um padrão globalmente dominante, o qual passou a estruturar as diferentes relações sociais de produção existentes em âmbito mundial em função do capital (QUIJANO, 2005).

Fernandes (2004) destaca as consequências da adaptação histórica e estrutural das nações latino-americanas ao desenvolvimento dependente, condição subordinada imposta pelas sociedades capitalistas hegemônicas que, aliadas ao projeto de dominação interna das burguesias nacionais, conduzem à reprodução dos ciclos de concentração da renda, do prestígio social e do poder:

\footnotetext{
As nações dependentes, permanecendo fiéis ao capitalismo, se condenam a um tipo de crescimento econômico e cultural, que pode ser descrito sob o conceito de "desenvolvimento dependente". Este conceito não significa, apenas, que elas estão sujeitas a "crescer" através dos efeitos diretos e indiretos da difusão cultural. Mas que a difusão cultural se desenrola, nos diversos níveis, em função de interesses e de dinamismos das sociedades hegemônicas, bem como das probabilidades de absorção de tais interesses e dinamismos por parte das sociedades heteronômicas. [...] o atraso cultural relativo e a dependência cultural não impedem certo avanço nas esferas da modernização e da absorção institucional. Por esse motivo, o "dilema real" dessas nações não é institucional e cultural; é econômico, social e politico. [...] Existe, como resíduo, um "problema educacional". Apesar de ele se originar no seio da escola e de se manifestar através dela, o seu fulcro
}

seus recursos e produtos; do sexo, seus recursos e produtos; da autoridade e de sua violência específica; da intersubjetividade e do conhecimento" (p. 119). 
estrutural e dinâmico localiza-se no modo pelo qual a sociedade brasileira participa da civilização ocidental moderna (FERNANDES, 2004, p. 285).

Conceição Paludo (2015), valendo-se do Materialismo Histórico Dialético como matriz teórica de análise, também afirma que "[...] a educação se faz a partir das e nas relações sociais" (p. 224), podendo seu sentido vincular-se tanto um campo de crítica ao sistema societário vigente, estabelecendo-se de forma contra hegemônica à dominação do capital, quanto ser desenvolvida a serviço da reprodução da ordem social estabelecida. A compreensão do fenômeno educativo requer, para a autora, que se estabeleçam e se explicitem as relações mutuamente condicionantes entre os projetos de sociedade e projetos de educação, os quais se relacionam dialeticamente em sua forma hegemônica (realidade histórica instituída) e utópica (anúncio de outro projeto societário).

No contexto histórico-cultural contemporâneo do Brasil e demais países da América Latina, os projetos nacionais burgueses não estão comprometidos com o desenvolvimento autônomo e soberano de seus povos e nações, mas sim a um projeto de consolidação de um capitalismo dependente, fundante de um regime de classes "[...] que destrói as bases estáticas e dinâmicas de equilíbrio de um sistema verdadeiramente nacional de poder" (FERNANDES, 2004, p. 305). Neste sentido, o processo educacional brasileiro e latino americano tende a relacionar-se prioritariamente com a promoção das condições necessárias para o avanço e a reprodução econômica e cultural de seus países sob o desígnio do desenvolvimento dependente ${ }^{4}$; ainda que, diante do caráter permanente e inacabado dos processos históricos e da perspectiva da superação das situações concretas de opressão, seja essencial "[...] conhecer o significado social do desenvolvimento educacional, se ele afeta ou não a organização societária dos papéis intelectuais e as relações dinâmicas da transmissão da cultura com a eficácia ou com a transformação de dada ordem social” (FERNANDES, 2004, p. 292-293).

\section{AS DIMENSÕES ESCOLARES E NÃO ESCOLARES DOS PROCESSOS EDUCATIVOS}

De acordo com Sposito (2003), a partir da década de $1960^{5}$, a sociologia da educação configurou seu objeto particular de investigação buscando estabelecer a contribuição que o sistema de ensino formal ofereceria para a reprodução da ordem social dominante, conceituando a escola enquanto instituição que expressaria e reforçaria as desigualdades presentes na estrutura das relações de força (reprodução social) e das relações simbólicas entre as classes (reprodução cultural). Entretanto, para autora, "[...] o recorte excessivamente estrutural [...] resultou, muitas vezes, no abandono dos caminhos rigorosos da pesquisa empírica", carecendo tais pesquisas de análises voltadas para o modo como a própria dinâmica de manifestação dos " [...] os processos internos à instituição [...] instalam relações de poder e produzem desigualdades, não só em decorrência das classes sociais, mas, também, de fundo étnico e de gênero" (p. 214). Todavia, segundo Sposito, a relevância analítica da instituição

\footnotetext{
4 "Esse é o ritmo histórico real, no qual as nações subdesenvolvidas descobrem que a "modernização" e o "nacionalismo" não bastam para imprimir o máximo de eficácia e de vitalidade a um certo padrão de civilização. Tudo isso patenteia que o importante vem a ser a posição a partir da qual determinada sociedade participa dos processos psicológicos, sociais e culturais pelos quais a civilização cresce e se difunde" (FERNANDES, 2004, p. 294).

${ }^{5}$ Esse período foi marcado pelos primeiros estudos realizados por Bourdieu, pela análise da escola desenvolvida por Baudelot e Establet, e pelas contribuições do marxismo estruturalista de Althusser (SPOSITO, 2003).
} 
escolar não implicaria necessariamente seu estudo empírico, visto que, a título de ilustração, consideramos que elementos oriundos de práticas sociais e processos educativos não escolares penetram, conformam e são ressignificados no interior da experiência escolar. Haveria, então, uma distinção e complementariedade entre duas possíveis formas de configuração da escola em sua constituição enquanto objeto de conhecimento científico: como unidade empírica de observação e enquanto categoria analítica.

No Brasil, desde a segunda metade do século XX, as problematizações do fenômeno educacional decorrentes das relações históricas estabelecidas entre o meio societário e suas instituições, ocorridas no interior de uma estrutura social rigidamente hierárquica, se objetivaram por meio da crítica à capacidade dos sistemas escolares em responder e se adequar aos desafios postos pela expansão decorrente de sua democratização, a qual passou a exigir por sua vez o alargamento da compreensão sociológica e política em relação aos elementos não escolares que permeiam a dinâmica de realização das práticas sociais escolares:

[...] o arco teórico ampliado e as novas pesquisas caminharam ao lado do movimento pela democratização do país, que voltou a incorporar no debate público a importância da educação escolar como direito democrático e a necessidade de se investigar e propor alterações profundas das práticas escolares, evitando-se os elementos mais perversos do sistema de ensino no que se refere à reprodução das desigualdades. Mas, se a escola continuou ocupando o foco de interesses da pesquisa sociológica sobre a educação, é preciso, ao menos, examinar perspectivas que contribuam para alargar nossa capacidade de compreensão e de análise. Dentre elas situa-se um recurso analítico e metodológico importante: a perspectiva não escolar (SPOSITO, 2003, p. 214-215).

A ampliação do escopo de atuação do sistema de ensino formal advinda da Constituição Federal de 1988 (BRASIL, 1988), a qual reconheceu a educação básica como um direito de todos e estabeleceu o Ensino Fundamental gratuito para todos os cidadãos, trouxe para o interior do ambiente escolar, de modo ainda mais contundente, as tensões da vida pública e as contradições políticas, sociais e econômicas constitutivas da sociedade brasileira. Para Conceição Paludo (2015), com a emergência da nova ordem social global, instituídas desde o decorrer da década de 1970 em resposta à situação de crise econômica do capitalismo então instaurada em âmbito mundial, “[...] o mais significativo a destacar, enquanto sustentação da direção das políticas públicas de educação, são as relações existentes entre o papel atribuído à escola, a concepção educativa e o padrão de acumulação flexível do capital"' (p. 229).

A mudança da conjuntura política e econômica mundial e o novo modelo neoliberal de acumulação capitalista ensejado por ela e imposto aos países em desenvolvimento pelos países hegemônicos, por meio da "Política de Ajustes Estruturais", coincidiu historicamente com o advento, no plano institucional, do novo regime democrático brasileiro, o qual manifestou o processo de luta e conquista pela promulgação do acesso universal à educação como direito de cidadania. Isto acarretou, internamente, um conjunto de transformações políticas e sociais decisivas para a compreensão da nova realidade nacional:

\footnotetext{
6 Política dirigida pelos organismos financeiros multilaterais (Fundo Monetário Internacional, Organização Mundial do Comércio e Banco Mundial) e orientada para a busca da estabilização monetária e da restrição de gastos em políticas sociais realizados pelo Estado.
} 
O mesmo processo de mutação social que constitui a "sociedade escolarizada", ou seja, a educação escolar como ferramenta essencial para a sobrevivência do indivíduo moderno no mundo (habilidades, conhecimentos e saberes, competência para uma melhor participação na esfera pública e afirmação de sua autonomia como sujeito), produz uma enorme crise das possibilidades de mobilidade social ascendente via escola pela escassa capacidade de absorção no mundo do trabalho dessa população escolarizada. As transformações estruturais nas últimas três décadas provocaram, entre outros efeitos, o desassalariamento e o desemprego. Essa crise da mobilidade social produz o aparecimento de uma nova desigualdade social - processos de inclusão precária e subalterna - e a multiplicação de desigualdades (SPOSITO, 2003, p. 220).

O contexto apresentado coloca o sistema público de ensino no centro das tensões da coexistência entre o campo escolar e não escolar, em suas experiências de intersecção e complementaridade variadas que constituem o fenômeno educativo. Assim, as pesquisa sobre educação escolar, tanto em relação à sua função social histórica quanto à sua dinâmica institucional de funcionamento, passam a requerer cada vez mais a investigação de processos educativos presentes em práticas sociais não escolares: seja pela necessidade de ampliação da compreensão densa dos sujeitos para além de sua experiência escolar, seja em relação à relevância dos elementos propriamente políticos e culturais de práticas sociais populares para a conformação dos projetos educacionais, seja ainda pela consideração analítica dos componentes burocráticos que decorrem da ação do Estado e que condicionam em parte seus padrões de sociabilidade interna. Neste sentido, o aparato jurídico-institucional do sistema de ensino também expressa parte dos conflitos que compõe a disputa empreendida pelos setores da sociedade em torno do projeto nacional que o Estado busca representar ${ }^{7}$, dentro da estrutura de relações sociais que promove e ao mesmo tempo contesta o desenvolvimento capitalista e dependente.

\section{EdUCAÇÃo POPUlAR, EDUCAÇÃo DE JOVENS E ADULTOS E DESIGUALdADE SOCIAL ESTRUTURANTE}

Se as leis de acumulação do capital se impõem enquanto síntese social no Brasil e na América Latina, os processos políticos de luta e resistência populares fomentaram, historicamente e de modo integrado, tanto as condições para o surgimento da Educação Popular enquanto campo crítico e contra hegemônico ao sistema societário vigente (PALUDO, 2015), quanto os elementos para a emergência da Educação de Jovens e Adultos (EJA) como campo pedagógico que se constitui a partir da existência de um vasto campo social de demanda por educação no Brasil (DI PIERRO; JOIA; RIBEIRO, 2001), resultado direto do processo de exclusão de amplas camadas da população às possibilidades de acesso e aos benefícios da cultura letrada e da escolaridade básica:

A história mostra que a educação escolar no Brasil nunca foi considerada como prioridade nacional: ela serviu apenas a uma determinada camada social, em detrimento das outras camadas da sociedade que permaneceram

\footnotetext{
${ }^{7}$ Boneti (2007), analisando as políticas públicas na atualidade, as considera atualidade, as considera “[ [...] o resultado da dinâmica do jogo de forças que se estabelecem no âmbito das relações de poder, relações essas constituídas pelos grupos econômicos e políticos, classes sociais e demais organizações da sociedade civil. Tais relações determinam um conjunto de ações atribuídas à instituição estatal, que provocam o direcionamento (e/ou o redirecionamento) dos rumos de ações de intervenção administrativa do Estado na realidade social e/ou de investimentos" (p. 74).
} 
iletradas e sem acesso à escola. Mesmo com a evolução histórico-econômica do país [...]; mesmo tendo, ao longo de cinco séculos de história, passado de uma economia agrária-comercial-exportadora para uma economia baseada na industrialização e no desenvolvimento tecnológico; mesmo com as oscilações políticas e revoluções por que passou, o Brasil não priorizou a educação em seus investimentos político-sociais e a estrutura educacional permaneceu substancialmente inalterada até nossos dias, continuando a agir como transmissora da ideologia das elites e atendendo de forma mais ou menos satisfatória apenas a uma pequena parcela da sociedade (MARÇAL RIBEIRO, 1990, p. 15)

Foi no contexto de mobilização, organização e participação de setores da sociedade civil em prol da ampliação do acesso à educação enquanto um direito de cidadania que a EJA emergiu enquanto tema de reflexão pública no Brasil, traduzindo a demanda por escolarização para pessoas que até então estavam excluídas da possibilidade de estudo. Isto ocorreu tardiamente, sobretudo, a partir dos anos 1940, sem que neste momento a tematização da EJA como tema de política educacional implicasse na formulação de uma metodologia específica a essa modalidade de ensino ou se constituísse como um paradigma pedagógico com estatuto próprio. Tal fato só ocorreria no início dos anos 1960, com a emergência de um movimento político e sociocultural mais amplo representado pela Educação Popular, a partir do qual Paulo Freire pôde realizar experiências populares de alfabetização crítica de adultos no Recife, ancoradas em uma pedagogia do oprimido. Segundo Paludo (2015):

O 'Movimento de Educação Popular' se fez no interior desse processo, na
direção da construção de fazer do povo expressão política de si mesmo, por
meio de organizações populares autônomas, imbuídas do desejo de construir
o 'poder popular'. Enquanto Movimento, a EP cumpriu um forte papel de
ação cultural no interior do campo e para além dele, constituindo-se em
mediação entre a realidade objetiva e o projeto de futuro em construção. Por
meio dele, articulado aos processos de luta e resistência, ia-se recompondo a
representação do real enquanto totalidade, superando a fragmentação, na
direção de uma concepção 'ético-política' (p. 226).

Tal proposta político-pedagógica fundamentava a alfabetização de adultos a partir da problematização dos educandos acerca de suas condições existenciais e das situações concretas de opressão por eles vivenciadas, fazendo emergir a politicidade do ato educativo voltado à transformação social e se colocando como contraponto às propostas pedagógicas que visavam à integração social da população aos processos de modernização conduzidos por forças exógenas (DI PIERRO; JOIA; RIBEIRO, 2001). Destarte, considerando que "[...] a pedagogia libertadora de Paulo Freire foi uma das fontes dessa explicitação do caráter político da educação, conformando a matriz do paradigma da educação popular que informou toda uma diversidade de práticas educativas formais ou não formais" (DI PIERRO; JOIA; RIBEIRO, 2001, p. 73), as propostas e iniciativas de alfabetização e pós-alfabetização de jovens e adultos passaram a buscar metodologias e conteúdos que fossem adequados ao universo cultural dos educandos.

De tal modo que, ao debater a complexidade cognitiva envolvida na construção/reconstrução de conhecimentos de jovens e adultos no contexto da organização do trabalho pedagógico da EJA, Stela C. Bertholo Piconez (1995) assevera:

Devolver à experiência o lugar que merece na aprendizagem dos conhecimentos necessários à existência (pessoal, social e profissional) passa pela constatação de que o sujeito constrói o seu saber ativamente ao longo do 
seu percurso de vida. Ninguém se contenta em receber o saber, como se ele fosse trazido do exterior pelos que detêm os seus segredos formais. A noção de experiência mobiliza uma pedagogia interativa e dialógica passa pela questão de construção coletiva com os interessados a partir de critérios que sejam fundamentais, entre eles a adequação do projeto pedagógico à realidade concreta na qual vive o aluno, isto é, a tomar a prática social como ponto de partida e critério de adequação (p. 14).

A mobilização da noção de experiência em sua dimensão educativa é fundamental para a construção de uma abordagem ampla e sistêmica do fenômeno educacional, visto que ela promove o reconhecimento e valoriza a importância da compreensão de processos educativos advindos de práticas sociais não escolares, assumidos em seu potencial formativo e como "[...] parte integrante da história da educação em nosso país, como uma das arenas importantes aonde vêm se empreendendo esforços para a democratização do acesso ao conhecimento" (DI PIERRO; JOIA; RIBEIRO, 2001, p. 58-59). Assim sendo, a EJA, ao considerar o que há de específico e de comum em cada trajetória formativa de seus educandos, a partir dos princípios da Educação Popular e da valorização dos saberes construídos nas práticas de trabalho e convivência no meio social, se constituiu enquanto campo de práticas e reflexões pedagógicas que ultrapassou os limites da educação escolar, em seu sentido estrito.

Entretanto, para que os interesses e os valores sociais que orientaram e buscam direcionar o crescimento institucional da educação brasileira deixem de mobilizar sua expansão na direção da continuidade da dependência educacional e cultural, é necessário que a sociedade mude suas relações com tais instituições, mobilizando e organizando formas de reivindicação que tencionem a busca de soluções e o uso dos recursos políticos para a produção de processos de integração e desenvolvimento nacional obtidos por meio da democratização da renda, do prestígio social e do poder. Desenvolvimento este que, para Florestan Fernandes (2004) deve expressar "[...] não qualquer tipo de transformação estrutural interna, mas a mudança social que, além de destruir os laços de dependência para com o exterior, permite àquela sociedade a conquista de semelhante posição de autonomia cultural relativa" (p. 296).

\section{CONSIDERAÇÕES}

Neste artigo, buscamos apresentar e discutir alguns fundamentos analíticos que evidenciam a relevância científica e social das pesquisas que investigam processos educativos decorrentes de práticas sociais diversas, em sua contribuição específica para os estudos acadêmicos que propõem uma perspectiva histórico-sociológica de compreensão crítica da educação brasileira. Como ponto de partida de tal argumentação, conceituamos a educação humana enquanto fenômeno ontológico, propondo uma abordagem ampla e sistêmica sobre seus modos de objetivação dentro de cada realidade histórico-cultural situada, os quais tendem a expressar os condicionamentos recíprocos que produzem e reproduzem os nexos existentes entre estrutura social, instituições societárias, relações intersubjetivas e processos de subjetivação.

Ademais, buscando a coerência entre aquilo que propomos e aquilo que realizamos, convém encerrar a presente argumentação apontando algumas questões educativas que emergem da realidade histórico-cultural presente e se colocam urgentes à sociedade brasileira. No contexto atual da grave crise humanitária gerada pela pandemia de Covid-19 em todo mundo, mas considerando especialmente a forma de manifestação aguda e caótica que ela assume no Brasil, diversas questões relevantes 
emergem do campo dos conflitos que se estabelecem no seio da sociedade nacional: Como as pessoas se educam no Brasil? Educam-se em relações sociais de que natureza? Esta educação vem constituindo individualidades capazes de realizar e participar de ações coletivas dialogicamente coordenadas e organizadas visando o bem comum? Produz individualidades sensíveis à alteridade humana e ao reconhecimento de outrem em sua liberdade existencial, para o difícil exercício ético de promoção recíproca das liberdades públicas e privadas? Quais os projetos educativos das instituições escolares? Eles atendem aos anseios de quais projetos de sociedade? Quais as implicações da ausência das aulas escolares presenciais nos processos de aprendizado e socialização promovidos pelas instituições de ensino? O ensino remoto é capaz de cumprir por si só as expectativas sociais que se expressam na formulação dos projetos educacionais atuais? Qual projeto societário que funda as condições objetivas do desenvolvimento dependente brasileiro? Qual o lugar da educação e da instituição escolar, em específico, neste processo?

Longe de esgotarem os dilemas enfrentados por nossa sociedade, as questões aqui apresentadas podem constituir um ponto de apoio para a reflexão sobre a relevância das pesquisas em práticas sociais e processos educativos para a compreensão das tensões existentes entre desigualdade social estruturante, escolarização e educação não escolar, nas relações que estabelecem com as disputas engendradas entre projetos societários hegemônicos e contra hegemônicos. Afinal, da forma com que nos educamos decorre o modo como seremos.

\section{REFERÊNCIAS}

ALIMONDA, H. La Colonialidad de la Naturaleza. Una aproximación a la Ecología Política Latinoamericana. In: ALIMONDA, H. (coord.). La Naturaleza Colonizada. Ecología política y minería en América Latina. Buenos Aires: Clacso - Ciccus, 2011. p. 19-59.

BONETI, L. W. Políticas públicas por dentro. Ijuí: Unijuí, 2007.

BRASIL. Constituição da República Federativa do Brasil. Brasília: Senado Federal, 1988.

BRAYNER, F. Fundamentos da educação: crise e reconstrução. Campinas: Mercado de Letras, 2015.

DI PIERRO, M. C.; JOIA, O.; RIBEIRO, V. M.. Visões da educação de jovens e adultos no Brasil. Cadernos CEDES, Campinas, v. 21, n. 55, p. 58-77, nov. 2001.

DUSSEL, E. Introducción a la filosofía de la liberación. 5. ed. Bogotá: Editorial Nueva América, 1995.

DUSSEL, E. La pedagógica latinoamericana (la antropológica II). In: DUSSEL, E. Filosofía ética latinoamericana: de la erótica a la pedagógica. México: Edicol, 1977. p. 123-198.

FERNANDES, F. Universidade e desenvolvimento. In: IANNI, O. (org.). Florestan Fernandes: sociologia crítica e militante. São Paulo: Expressão Popular, 2004. p. 272-316.

FIORI, E. M. Aprender a dizer a sua palavra. In: FIORI, E. M. Educação e Política: textos escolhidos volume 2. 2. ed. Porto Alegre: Editora da UFRGS, 2014a. p. 67-81.

FIORI, E. M. Conscientização e educação. In: FIORI, E. M. Educação e Política: textos escolhidos volume 2. 2. ed. Porto Alegre: Editora da UFRGS, 2014b. p. 83-104.

FIORI, E. M. Educação Libertadora. In: FIORI, E. M. Textos escolhidos, Vol. II, Educação e Política. Porto Alegre: L\&PM, 1991. p. 83-95.

FREIRE, P. Pedagogia do oprimido. 50. ed. Rio de Janeiro: Paz e Terra, 2011. 
Diogo Marques Tafuri

FREIRE, P. Extensão ou comunicação? 13. ed. Rio de Janeiro: Paz e Terra, 2006.

MARÇAL RIBEIRO, P. R. Educação escolar no Brasil: problemas, reflexões e propostas. Araraquara: UNESP, 1990. (Coleção Textos, Vol. 4).

MERLEAU-PONTY, M. Fenomenologia da percepção. 3. ed. São Paulo: Martins Fontes, 2006.

OLIVEIRA, M. W.; SILVA, P. B. G.; GONÇALVES JUNIOR, L.; MONTRONE, A. V. G.; JOLY, I. Z. L. Processos educativos em práticas sociais: reflexões teóricas e metodológicas sobre pesquisas em espaços sociais. In: OLIVEIRA, M. W.; SOUSA, F. R. (org.). Processos educativos em práticas sociais: pesquisas em educação. São Carlos: EdUFSCar, 2014. p. 29-46.

PALUDO, C. Educação popular como resistência e emancipação humana. Cadernos CEDES, v. 35, n. 96, p.219-238, 2015.

PICONEZ, S. C. B. A Reconstrução dos conhecimentos na educação escolar de jovens e adultos e a organização do trabalho pedagógico. Inep, $1995 . \quad$ Disponível em: http://portal.inep.gov.br/documents/186968/486324/A+Reconstru\%C3\%A7\%C3\%A3o+dos+Conhecimen tos+na+Educa \% C3\% A7\%C3\% A3o+Escolar+de+Jovens+e+Adultos+e+a+Organiza\%C3\%A7\%C3\%A30 +do+Trabalho+Pedag\%C3\%B3gico/28478f8c-c5fd-4353-8813-240e24ee877a?version=1.1. Acesso em: 14 abr. 2021.

QUIJANO, A. Colonialidade do poder, eurocentrismo e América Latina. In: LANDER, E. (org.). A colonialidade do saber: eurocentrismo e ciências sociais. Perspectivas latino-americanas. Buenos Aires: Clacso, 2005. p. 107-130. (Colección Sur Sur).

SILVA, P. B. G. Práticas sociais e processos educativos: da vida e do estudo até o grupo de pesquisa. In: M. W. OLIVEIRA; F. R. de SOUSA (org.) Processos educativos em práticas sociais: pesquisas em educação. São Carlos: EdUFSCar, 2014. p. 19-27.

SILVA, P. B. G. Educação e identidade dos negros trabalhadores rurais do limoeiro. 1987. 293 p. Tese (Doutorado em Educação) - Universidade Federal do Rio Grande do Sul, Porto Alegre, 1987.

SPOSITO, M. P. Uma perspectiva não escolar no estudo sociológico da escola. Revista USP, São Paulo, n. 57 , p. 210-226, mar./maio 2003.

TAFURI, D. M. Educação e luta de trabalhadores sem-terra como expressão do contraditório. Práxis Educacional, v. 17, n. 45, p. 1-20, 2021.

TAFURI, D. M. Deus e o Diabo na terra da cerca: a educação como expressão da luta pela terra no Assentamento Santa Helena. 2019. 241 f. Tese (Doutorado em Educação) - Universidade Federal de São Carlos, São Carlos, 2019.

TAFURI, D. M.. A experiência educativa da gestão de um banco comunitário na periferia de São Carlos/SP. 2014. 193 f. Dissertação (Mestrado em Educação) - Universidade Federal de São Carlos, São Carlos, 2014.

TAFURI, D. M.; GONÇALVES JUNIOR, L. Terra, trabalho e dinheiro: dilemas e tensões da condição camponesa no assentamento Santa Helena. Retratos de Assentamentos, v. 23, n. 1, p. 10-38, 2020.

TAFURI, D. M.; GONÇALVES JUNIOR, L. Fundamentos teórico-conceituais da pesquisa em práticas sociais e processos educativos. Educação Unisinos, v. 21, p. 40-49, 2017.

TAFURI, D. M.; GONÇALVES JUNIOR, L. Educação, cultura e economia solidária: a experiência dos trabalhadores do Banco Nascente. Trabalho \& Educação (UFMG), v. 24, p. 31-50, 2015.

Recebido em: 14 abr. 2021.

Aprovado em: 27 abr. 2021.

Motricidades: Rev. SPQMH, v. 5, n. 1, p. 4-16, jan.-abr. 2021 | ISSN 2594-6463 |

DOI: http://dx.doi.org/10.29181/2594-6463-2021-v5-n1-p4-16 